\title{
FILMS LDPE/LLDPE MADE FROM POST - CONSUMER PLASTICS: PROCESSING, STRUCTURE, MECHANICAL PROPERTIES
}

\section{Dorota Czarnecka-Komorowska', Karolina Wiszumirska², Tomasz Garbacz ${ }^{3}$}

\author{
Poznan University of Technology, Institute of Materials Technology, Polymer Processing Division, Piotrowo 3 \\ Street, 61-255 Poznan, Poland, e-mail: dorota.czarnecka-komorowska@put.poznan.pl \\ 2 Poznan University of Economics and Business, Faculty Commodity Science, Department of Commodity \\ Science and Ecology of Industrial Products, Poznan, Poland, e-mail: karolina.wiszumirska@ue.poznan.pl \\ 3 Lublin University of Technology, Mechanical Engineering Faculty, Nadbystrzycka 38, 20-618 Lublin, Poland, \\ e-mail: t.garbacz@pollub.pl
}

Received: 2018.05.21

Accepted: 2018.08.01

Published: 2018.09.01

\begin{abstract}
The paper presents the results of the investigation into the themo-mechanical, rheological and structural properties of films made from recycled polyethylenes in the "foil-to-foil" system, the comparative material were films made from primary raw materials. The films were prepared by melt mixing technique in a single screw extruder. Primary polyethylenes, recyclates and their blends were used. The aim of the research was to determine the quality of the materials derived from the closed process of the recycling of polyethylene film in comparison to virgin plastics. The mechanical properties of the films were measured by tensile test and puncture test. The morphology was studied using polarized light microscopy (POM) and FT-IR measurements. DSC and shrinkage were used to determine thermal behavior and the degree of crystallinity. The results showed that the obtained recycled blends rLDPE/rLLDPE are high-quality material with good processing properties susceptible to the production of thin films. Studies on the mechanical properties of the recycled blends showed an increase in tensile strength and elongation. An increase in the melting temperature and heat of fusion, as determined from DSC, was observed with an increase in the recycled blends. Puncture results demonstrated that the post-consumer recycled film was more strength than the film made from virgin plastics. Thus, these materials may serve as valuable recycled plastics useful for packaging applications.
\end{abstract}

Keywords: polyethylenes, films, recycling, extrusion, crystallinity, FTIR, mechanical properties.

\section{INTRODUCTION}

Post-consumer packaging waste made of polyolefins in accordance with the circular economy philosophy is a valuable resource for reprocessing. Landfill and waste incineration is associated with environmental risks and is considered to be economically inefficient.

The main source of LDPE and LLDPE in the waste stream intended for recycling are packaging films (bags, wraps, stretch film) and agricul- tural films. The short life cycle of these products on the market determines a small degree of the degradation of these products. What is a factor contributing to the increase of the degradation of polyethylene is the mechanical recycling process in which the chain of macromolecules is broken/ cracked under the influence of shear stress, for example during grinding and/or extrusion in the viscoelastic state [14]. In the case of reprocessing of LDPE and LLDPE originating from packaging materials, it can be assumed that the observed 


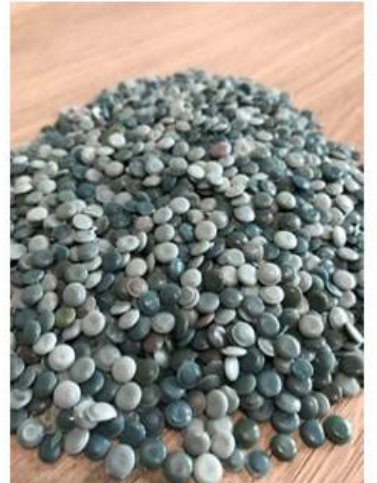

a)

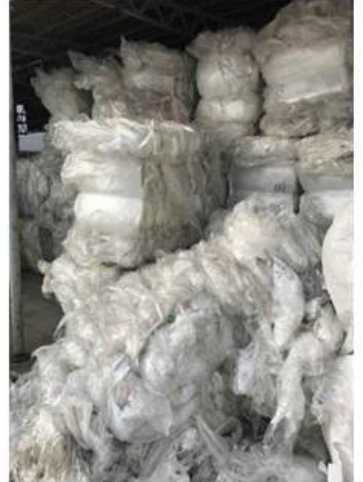

b)

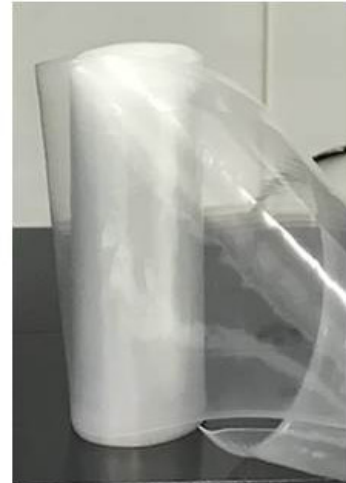

c)

Fig. 1. Post-consumer film wastes: a) inputs to process, b) outputs to process (regranulate), c) final product

degree of degradation of the blends will be insignificant, and recycled rLDPE or rLLDPE will be characterized by processing [6] and usage properties similar to virgin polyethylenes. This phenomenon may be explained by two mechanisms: firstly, the stream of waste from polyethylene is fed with materials processed only once; secondly, the recycling process, despite the impact of many degrading factors, such as temperature, shear stress and water, may not destroy plastics to such high a degree as it is assumed. The properties of regranulates can be shaped through the production of blends with virgin materials [11], the modification with fillers [2, 4, 9], foaming [16], or production of blends based on recyclates [3]. LLDPE processors sometimes use a small addition of LDPE to the mixture by the film blowing process [7] to increase the stability and uniformity and improve the properties of the film. Similarly, the addition of LLDPE to LDPE results in an increase in the crystallization temperature. Blends containing minor amounts of LDPE in LLDPE (and LLDPE in LDPE) show a synergistic effect on increasing the strength of blends [14].

\section{PREPARATION OF RESEARCH MATERIALS}

Two kinds of regranulates from low density polyethylene (LDPE) and linear low density polyethylene (LLDPE) from the "foil-to-foil" collection and recycling system were used for the research. The regranulates were made of films that had been previously cleaned, shredded, washed, dried and finally packed. The LDPE regranulates were produced from post-consumer plastic waste and stretch film used in logistics to secure pallet load units. The manufacturing chain of films was presented in Figure 2. Thin films were extruded from the regranulates and virgin materials in the following proportions: $50 \mathrm{wt} \% \mathrm{rLDPE} / 50 \mathrm{wt} \%$ rLLDPE (abbreviation rA50/rB50), $30 \mathrm{wt} \%$ rLDPE/70 wt $\%$ rLLDPE (abbreviation rA30/ rB70), rLDPE (abbreviation rA), rLLDPE (abbreviation $\mathrm{rB}$ ), where " $\mathrm{r}$ " means regranulates, 100 $\mathrm{wt} \%$ LDPE (abbreviation A) and LLDPE (abbreviation $\mathrm{B}$ ), which were compared with virgin polymers. The pictures of raw materials, regranulates and films are presented in Figure 1a - 1c.

\section{Films processing}

The films were prepared using a slot die extrusion technique. Six different materials (virgin and regranulates) and two blends were melt-mixed using a Brabender single screw extruder. Before extrusion, the material was dried at $80^{\circ} \mathrm{C}$ in a Shine hot drying oven for $120 \mathrm{~min}$. The screw diameter of the extruder was $25 \mathrm{~mm}$ and the length/ diameter (L/D) ratio was 34:1. The temperature profile of the extruder (from intake zone to die) was $225-165-201-215-220^{\circ} \mathrm{C}$, and the screw rotational speed $10 \mathrm{rpm}$. The melt pressure was 50-55 bar and the throughput was $1 \mathrm{~kg} / \mathrm{h}$. The blend was cooled in cooling chill rollers and then stretched.

\section{TEST METHODS}

The mechanical properties of the samples were determined by tensile tests performed using a universal testing machine: a Zwick/Roell Z005 (Ulm, Germany). The samples were belt-shaped, according to the PN-EN ISO 527-3 standard [21]. The tensile tests were run at room temperature. Tensile characteristics were measured at $200 \mathrm{~mm} / \mathrm{min}$ cross head speed. Ultimate tensile strength $\left(\sigma_{\mathrm{M}}\right)$, elongation at strength $\left(\varepsilon_{\mathrm{M}}\right)$, tensile stress at break $\left(\sigma_{\mathrm{B}}\right)$, an- 


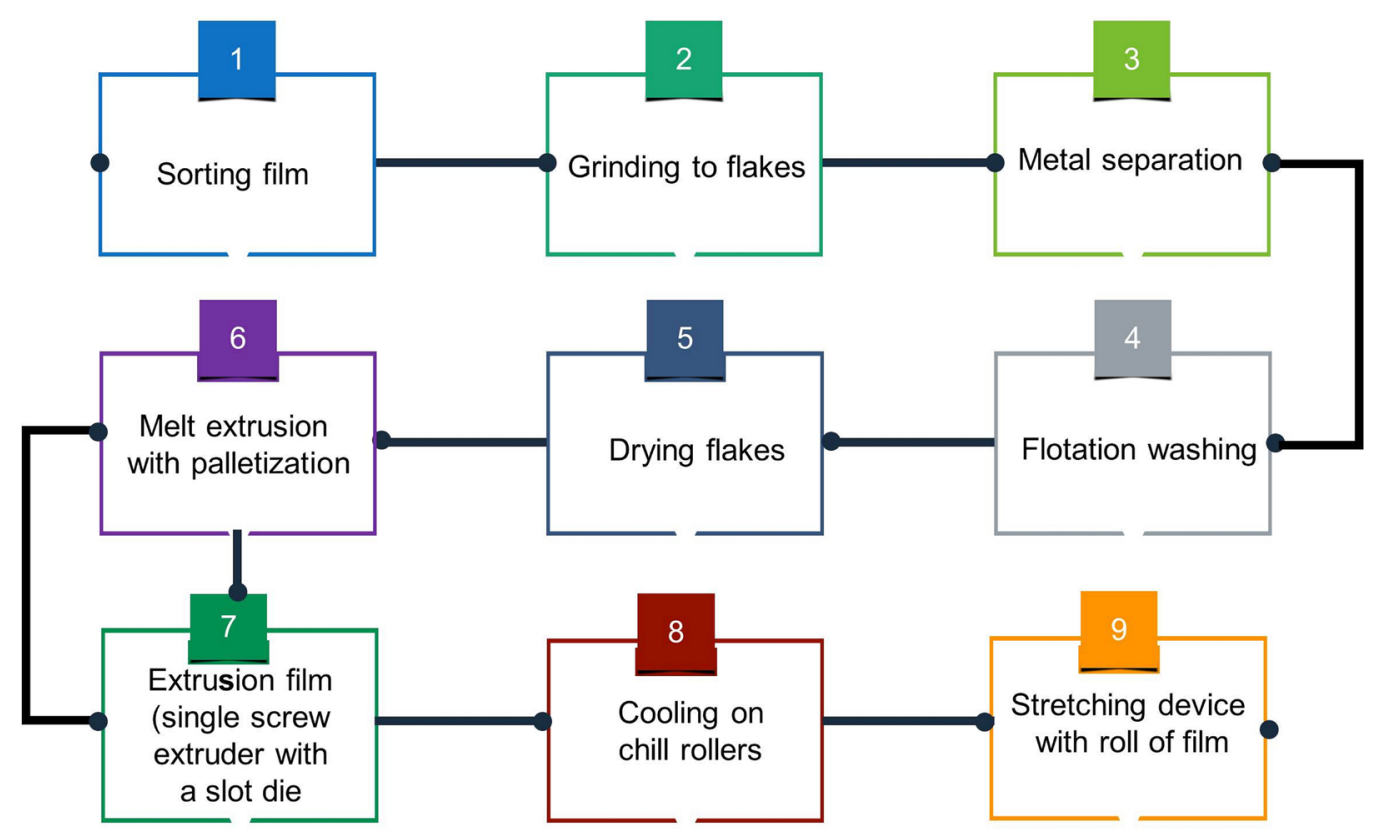

Fig. 2. Manufacturing chain of production

delongation at break $\left(\varepsilon_{\mathrm{B}}\right)$, were evaluated from the tensile stress-strain curves. The reported data were the average of the results of 10 specimens.

Puncture tests measure this behavior using a pointed tip with a diameter of $0.8 \mathrm{~mm}$. This test is also known as the Parker Ball-Point Test. In this test (Fig. 3), a strip specimen is gripped in the lower specimen holder. It is punctured from above with an exchangeable probe to measure the maximum penetration force. Puncture resistance is the relative ability of a material to inhibit the progression of a tear by a tip. Testing methods determine the resistance to the penetration of a probe at a single constant test speed. A test performed under standard conditions imparts a biaxial stress. The puncture will depend on the nature of a puncture attempt, with the two most important features being point sharpness and force. Puncture strength is a measure of the maximum force or energy required to penetrate a material [18].

The puncture tests were performed on a Zwick/Roell (Ulm, Germany) Z005 tension machine with a $1 \mathrm{kN}$ load cell at a room temperature of $23^{\circ} \mathrm{C}$. The tests were conducted with a crosshead speed of $50 \mathrm{~mm} / \mathrm{min}$. The force and the displacement were measured and recorded. Each test was repeated ten times.

The thermal behavior of the films was studied using a differential scanning calorimeter (Netzsch, DSC 204 F1 Phoenix, Selb, Germany) operating under nitrogen flow (150 ml/min) (ISO 11357-2:2013)
[20]. The samples of about $5 \mathrm{mg}$ were heated up to $20{ }^{\circ} \mathrm{C}$ and held there in order to eliminate the thermal and mechanical prehistory. Next, the samples were cooled to $170^{\circ} \mathrm{C}$ at a cooling rate of $10^{\circ} \mathrm{C} / \mathrm{min}$ and held there for five minutes, and finally reheated

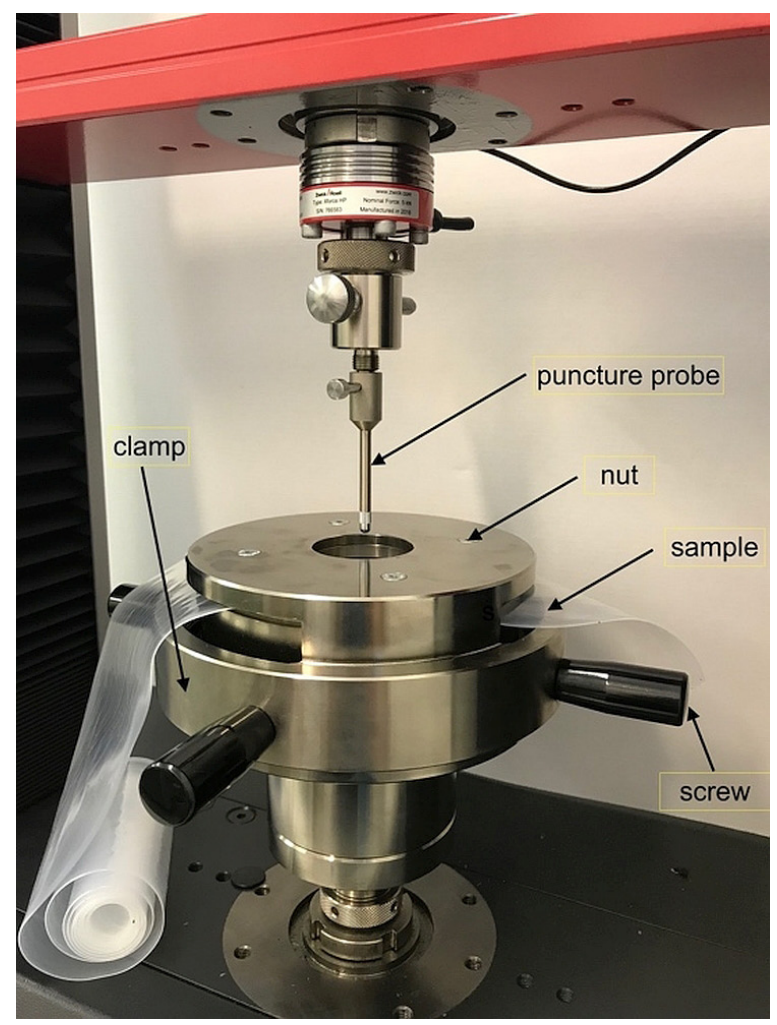

Fig. 3. Schematic of the puncture test 
again to $200^{\circ} \mathrm{C}$ at the same rate. The crystallinity $\left(\mathrm{X}_{\mathrm{c}}\right)$ of the samples was determined from the values of enthalpy melting registered during the second heating, using the following equation:

$$
X_{c}(\%)=\frac{\Delta H_{m}}{\Delta H_{m}^{0}}
$$

where $\Delta \mathrm{H}_{\mathrm{m}}$ is the melting enthalpy of the samples, $\Delta \mathrm{H}^{0}{ }_{\mathrm{m}}$ is the melting enthalpy for a $100 \%$ crystalline of polymer - this latter measurement was taken as $293 \mathrm{~J} / \mathrm{g}$ for PE [17].

FTIR spectra of virgin LDPE and LLDPE, recycled polymers and their recycled blends were carried out using a Perkin Elmer Spectrum 100 spectrometer in ATR mode. The spectra were collected over the range of $4000-400 \mathrm{~cm}^{-1}$ at room temperature with an accumulation of 11 scans at a resolution of $4 \mathrm{~cm}^{-1}$.

The study was performed according to PNEN ISO 11501:2005 [22]. The dimensions of the sample were adjusted to the width of the film obtained. Samples measuring 50 x $50 \mathrm{~mm}$ and marked directions were placed in a ceramic container filled with talc, then the samples were placed in the chamber dryer at $100^{\circ} \mathrm{C}$ for 5 minutes, then, after cooling, the contraction was measured and the percentage shrinkage (data expressed with a negative sign) or percentage increase of the sample length was expressed (data expressed with a positive sign). The test was carried out in five repetitions for each type of material.

Apolarized optical light microscope (POM) (Nikon Eclipse E400, Kanagawa, Japan), equipped with an Opta-Tech camera, with the

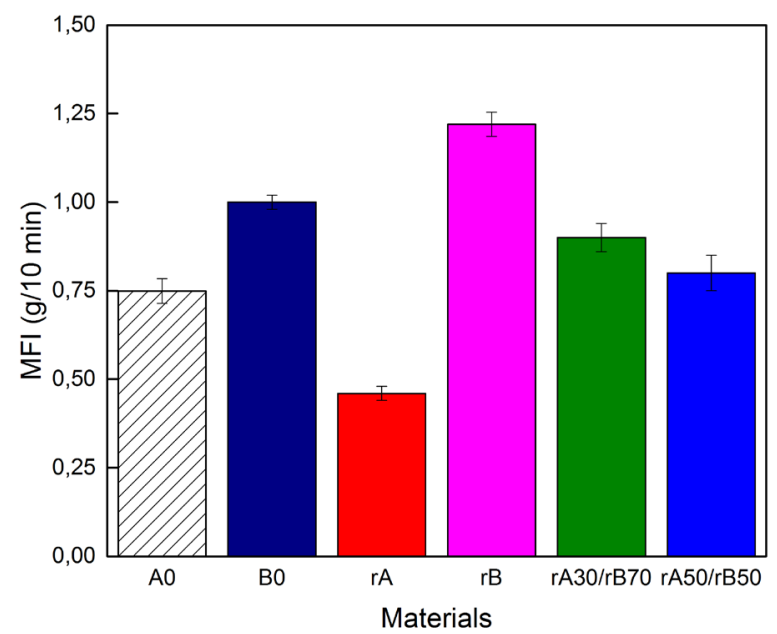

Fig. 4. Mass flow index (MFI) for virgin and recycled material LDPE and LLDPE and recycled blends magnification of the image of 25 times was used to study the films surface morphology.

\section{RESULTS AND DISCUSSIONS}

\section{Processing behavior of films}

The MFI is a measure of the ease of flow of the polymer melt. The MFI is an indirect measure of molecular weight, with high MFI corresponding to a low molecular weight of polymers [10]. The results of MFI shown in Figure 4 indicate that MFI for recycled LLDPE film was higher (about 25\%) in comparison to virgin polymer, which indicates that the rLLDPE film would have shorter chains and therefore low molecular weight and lower viscosity. On the other hand, we can see that MFI of rLDPE films is lower (about 30\%) than pure LDPE. This decrease was attributed to the thermomechanical degradation of the molecular chain.

A solution to this problem is to recycle blend LLDPE with LDPE. The resulting blend combines good mechanical properties and processing properties of LLDPE/LDPE blends. As shown in Fig. 4, the mass flow index of LDPE/LLDPE film is improved by the addition of $50 \mathrm{wt} \%$ recycled LDPE to LLDPE. It shows that the manufacturing process of films based on recycled materials is easier and cheaper.

\section{Tensile behavior of films}

The typical tensile stress-strain curves of virgin and recycled LDPE and LLDPE, and recycled blends is presented in Fig. 5

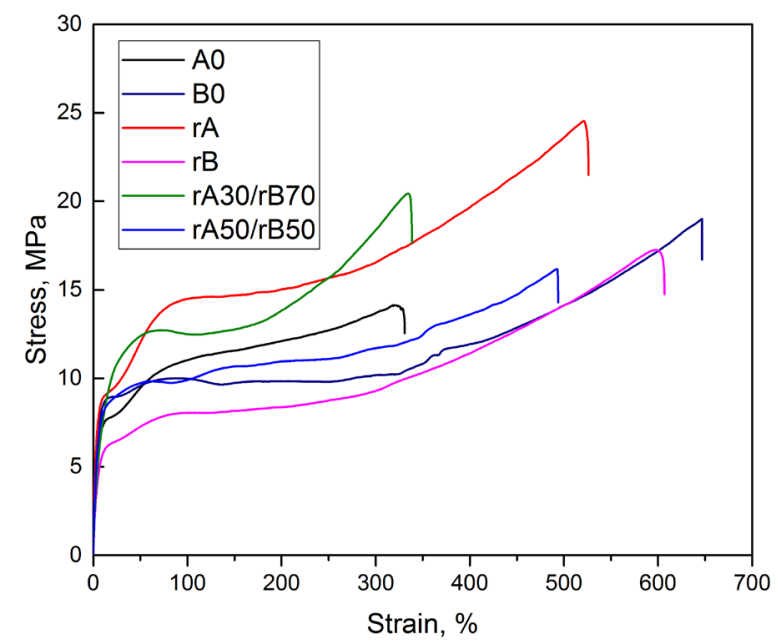

Fig. 5. Tensile stress-strain curves of virgin and recycled LDPE and LLDPE and recycled blends 
Table 1. Mechanical properties with standard deviations of virgin and recycled LDPE and LLDPE and recycled blends

\begin{tabular}{|c|c|c|c|c|}
\hline Samples & $\begin{array}{c}\text { Ultimate tensile } \\
\text { strength, } \mathbf{s}_{\mathbf{M}}(\mathbf{M P a})\end{array}$ & $\begin{array}{c}\text { Elongation at strength, } \mathbf{e}_{\mathrm{M}} \\
\mathbf{( \% )}\end{array}$ & $\begin{array}{c}\text { Tensile stress at break, } \mathbf{s}_{\mathrm{B}} \\
\mathbf{( M P a})\end{array}$ & $\begin{array}{c}\text { Elongation at break, } \mathbf{e}_{\mathrm{B}} \\
(\%)\end{array}$ \\
\hline $\mathrm{A} 0$ & $13.73 \pm 0.90$ & $322 \pm 50$ & $12.40 \pm 1.38$ & $327 \pm 50$ \\
\hline $\mathrm{B} 0$ & $18.20 \pm 0.70$ & $644 \pm 5$ & $16.50 \pm 4.00$ & $638 \pm 30$ \\
\hline rA & $24.10 \pm 1.52$ & $516 \pm 14$ & $21.90 \pm 2.26$ & $522 \pm 14$ \\
\hline rB & $17.00 \pm 1.57$ & $554 \pm 35$ & $14.50 \pm 1.68$ & $565 \pm 37$ \\
\hline rA30/rB70 & $27.50 \pm 1.24$ & $340 \pm 10$ & $25.70 \pm 2.83$ & $350 \pm 20$ \\
\hline rA50/rB50 & $18.50 \pm 1.70$ & $543 \pm 17$ & $16.40 \pm 1.95$ & $523 \pm 65$ \\
\hline
\end{tabular}

Table 2. The data for average puncture strength of the films

\begin{tabular}{|c|c|c|c|c|c|c|}
\hline Properties & A0 & B0 & rA & rB & rA30/rB70 & rA50/rB50 \\
\hline $\begin{array}{c}\text { Puncture strength } \\
(\mathrm{N} / \mathrm{mm})\end{array}$ & $347.0 \pm 32.9$ & $340 \pm 9.1$ & $259.0 \pm 48.8$ & $283.0 \pm 66.1$ & $336.0 \pm 67.7$ & $358.0 \pm 22.0$ \\
\hline
\end{tabular}

The elongation at break $\left(\varepsilon_{\mathrm{B}}\right)$, ultimate tensile strength $\left(\sigma_{\mathrm{M}}\right)$ and tensile stress at break $\left(\sigma_{\mathrm{B}}\right)$ values for recycled LDPE and LDPE films, their blends and pure polymers films have been evaluated, as listed in Table 1. The results showed a significant increase of tensile properties like strength and elongation at break for recycled LDPE, and 50/50LLDPE, which corresponds to an increase of up to $50 \%$. In the case, when the recycled material is LLDPE, the opposite behavior was observed, and this may be due to the mechanical degradation of the long side chain branching in LLDPE. Comparing to the pure LDPE, it was found that the maximum rise of ultimate strength was noted for LDPE/LLDPE blend with 70\%wt. LLDPE (about $100 \%$ ), but the addition of a larger amount of LLDPE makes processability difficult.

As seen in table 1, for the LDPE blend with $30 \%$ wt. LLDPE, we observed an increase in both the tensile strength and elongation at break, comparing to pure LDPE. The elongation at break of the film made based on recycled polymers increased from $327 \%$ to $520 \%$, which corresponds to an increase of approx. $60 \%$. The increase in the tensile stress at break of $\mathrm{r} 50 \mathrm{~A} / \mathrm{r} 50 \mathrm{~B}$ blend is attributed to the increase in the degree of crystallinity. These results are in a good agreement with the DSC results.

\section{Puncture behaviors}

The puncture test showed a clear benefit of the use of regranulate blends compared to the properties of monofilms from regranulates (e.g. Table 2; Fig. 6). It turned out that, in relation to materials obtained from recycling, the films from virgin polyethylene had puncture strength lower by about $25 \%$ for LDPE and about $17 \%$ for LLDPE, but when using a combination of LDPE and LLDPE regranulates, synergy was demonstrated. The blends with the proportions $\mathrm{rA30/rB70}$ had about $30 \%$ higher strength to recycled monofilm and rA50/rB50 blend had puncture strength higher by about $40 \%$ compared to the rLDPE and about $27 \%$ compared to the rLLDPE.

\section{Thermal characterization of films}

The curves of the DSC melting and cooling scans of the virgin and recycled LDPE and LLDPE and their blends are shown in Fig. 7 and 8, respectively. The DSC results are summarized in

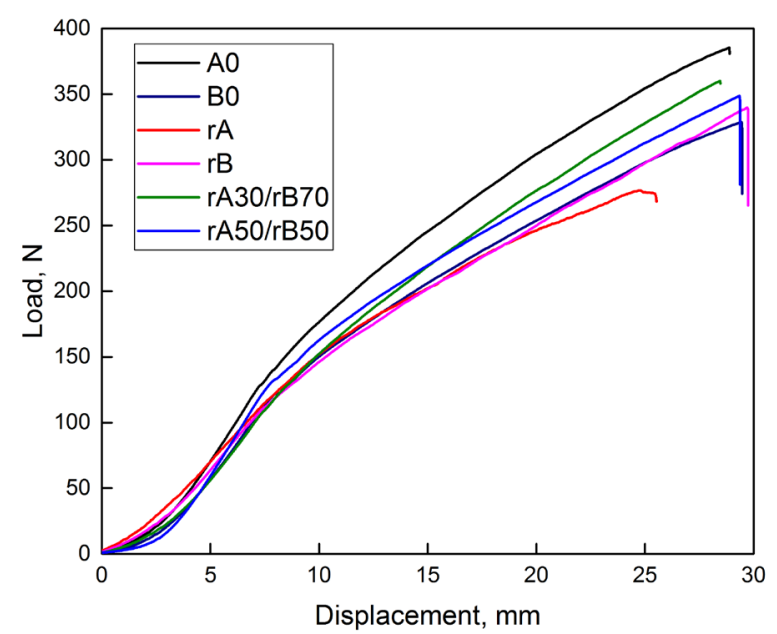

Fig. 6. The puncture strength for virgin LDPE and LLDPE films and recycled blends 
Table 3. DSC data of virgin LDPE and LLDPE films and recycled blends (cooling and heating rate: $20 \% / 10 \% \mathrm{~min}$ )

\begin{tabular}{|c|c|c|c|c|}
\hline Samples & $\mathbf{T}_{\mathrm{m}}\left({ }^{\circ} \mathbf{C}\right)$ & $\mathbf{D H}_{\mathrm{m}}(\mathbf{J} / \mathbf{g})$ & $\mathbf{T}_{\mathrm{c}}\left({ }^{\circ} \mathbf{C}\right)$ & $\mathbf{X}_{\mathrm{c}}(\%)$ \\
\hline $\mathrm{A} 0$ & 111.7 & -82.83 & 97.4 & 32 \\
\hline $\mathrm{B} 0$ & 122.7 & -100.7 & 106.0 & 34 \\
\hline rA & 126.7 & -112.8 & 111.7 & 38 \\
\hline rB & 119.9 & -99.06 & 105.7 & 33 \\
\hline rA30/rB70 & 123.4 & -97.42 & 109.2 & 33 \\
\hline rA50/rB50 & 124.2 & -113.1 & 110.1 & 39 \\
\hline
\end{tabular}

Table 3. As seen in Figure 7, the degree of crystallinity $(\mathrm{Xc})$ increases with an increase in the LDPE content in the blends (about 20\%). Furthermore, we also found that the $50 \%$ wt. addition of the LDPE enhances the crystallinity of the LLDPE.

Figure 7 shows the DSC heating scans of rLDPE having varying amounts of rLLDPE. Virgin LDPE and LLDPE showed a single melting endotherm in the temperature range of 100-130 ${ }^{\circ} \mathrm{C}$ with a peak (endotherm) at $111.7^{\circ} \mathrm{C}$ for LDPE and at $126.7^{\circ} \mathrm{C}$ for virgin LLDPE. In the entire blends sample, one exothermic peak to the curing reaction in the temperature at $255^{\circ} \mathrm{C}$ was observed in the heating scans of samples.

Figure 8 shows the crystallization curve of virgin and recycled LDPE and LLDPE and their recycled blends. From the area under the crystallization exotherm, the heat of crystallization was calculated. The results are summarized in Table 3.

A significant increase in the crystallization temperature was obtained for recycled blends. The blends achieve a 50\% faster degree of crys- tallinity, which should be understood as the possibility of a shorter processing cycle.

\section{FT-IR characterization of films}

Recycled polyethylenes were investigated using FTIR spectroscopy and compared with virgin polymers (Fig. 9). Characteristic bands for polyethylene were observed at wavelength $2915 \mathrm{~cm}^{-1}$ (C-H bond, antisymmetric stretching) and 2848 $\mathrm{cm}^{-1}$ (C-H bond, symmetric stretching) and 1463 $\mathrm{cm}^{-1}$ (C-H bond, deformation), responsible for the presence of alkyl groups. The analysis of the blends spectra showed contamination from rLLDPE, which did not appear in the spectra of the original polymers. Bands from impurities are clear and visible at wavelength $1740 \mathrm{~cm}^{-1}$ (usually assigned to R-CO-OR', $\mathrm{C}=\mathrm{O}$ stretching where $\mathrm{R}$ and $\mathrm{R}^{\prime}$ are alkyl groups); $1240 \mathrm{~cm}^{-1}$ (is due to the asymmetric C-C-O stretching involving the carbon in aromatic ring) and at $1015-1017 \mathrm{~cm}^{-1}$ wavelength. Impurities can come from additional ingredients used in the production of LLDPE stretch film.

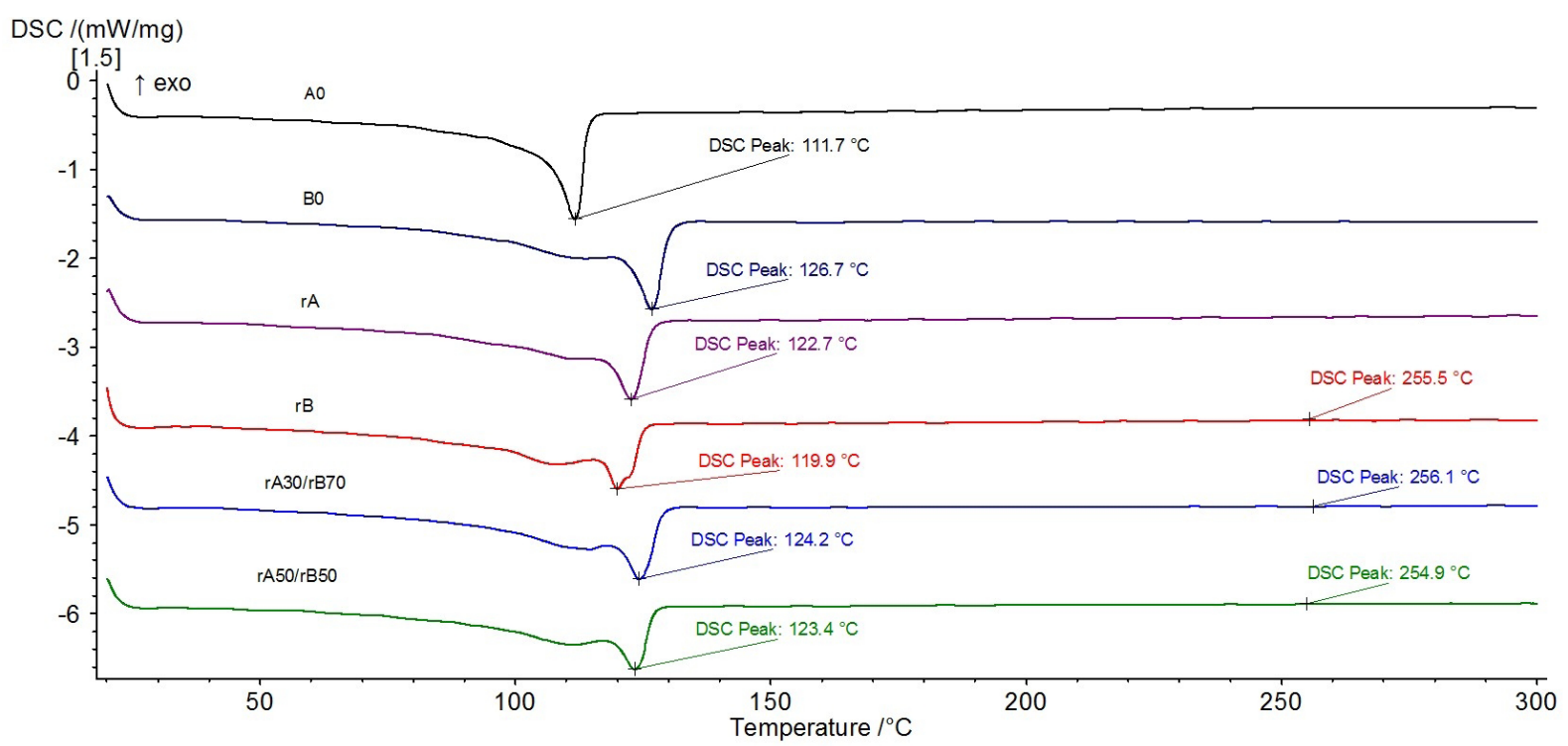

Fig. 7. DSC endotherms for virgin and recycled LDPE and LLDPE and recycled blends 


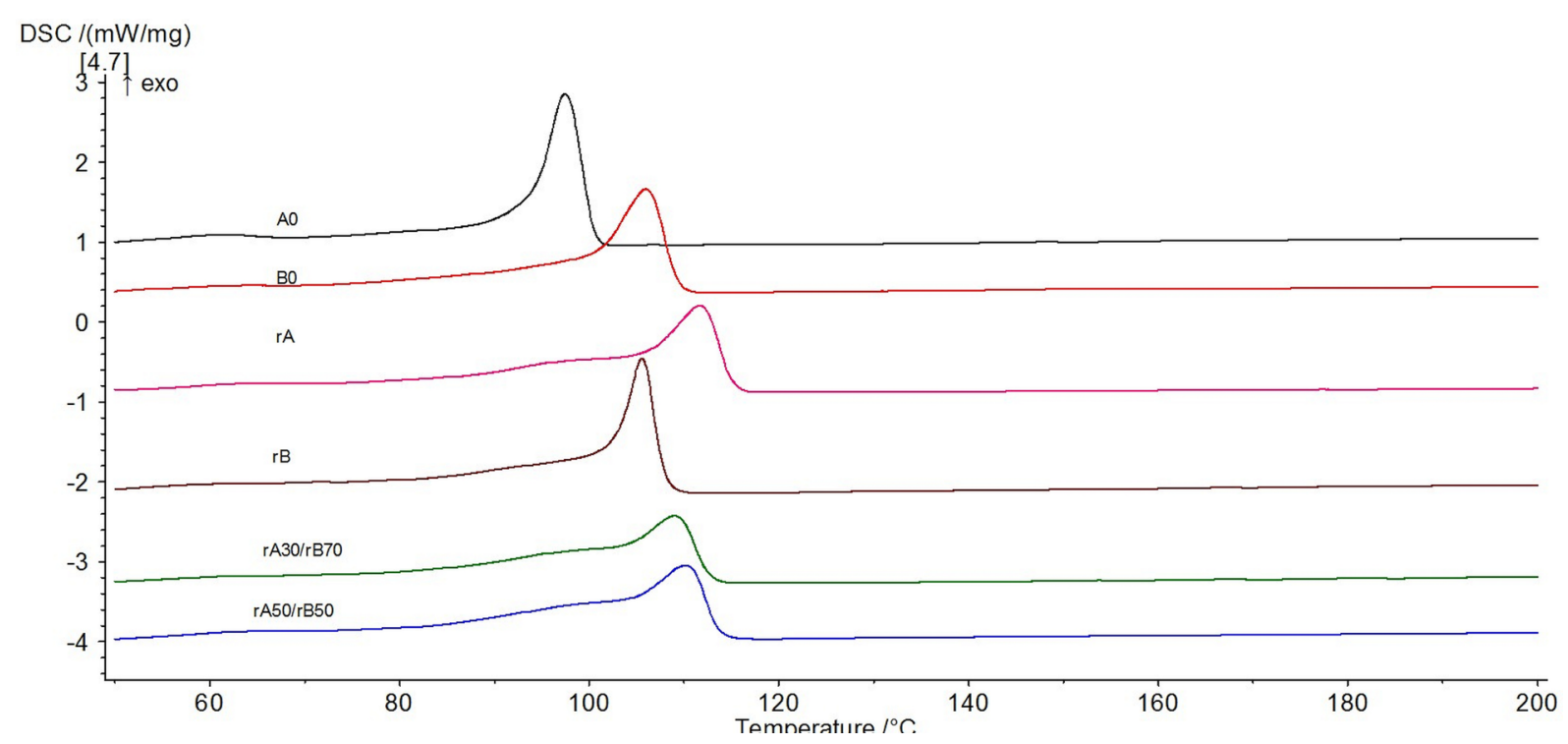

Fig. 8. DSC cooling thermograms for virgin and recycled LDPE and LLDPE and recycled blends. Cooling rate is $10^{\circ} \mathrm{C} / \mathrm{min}$

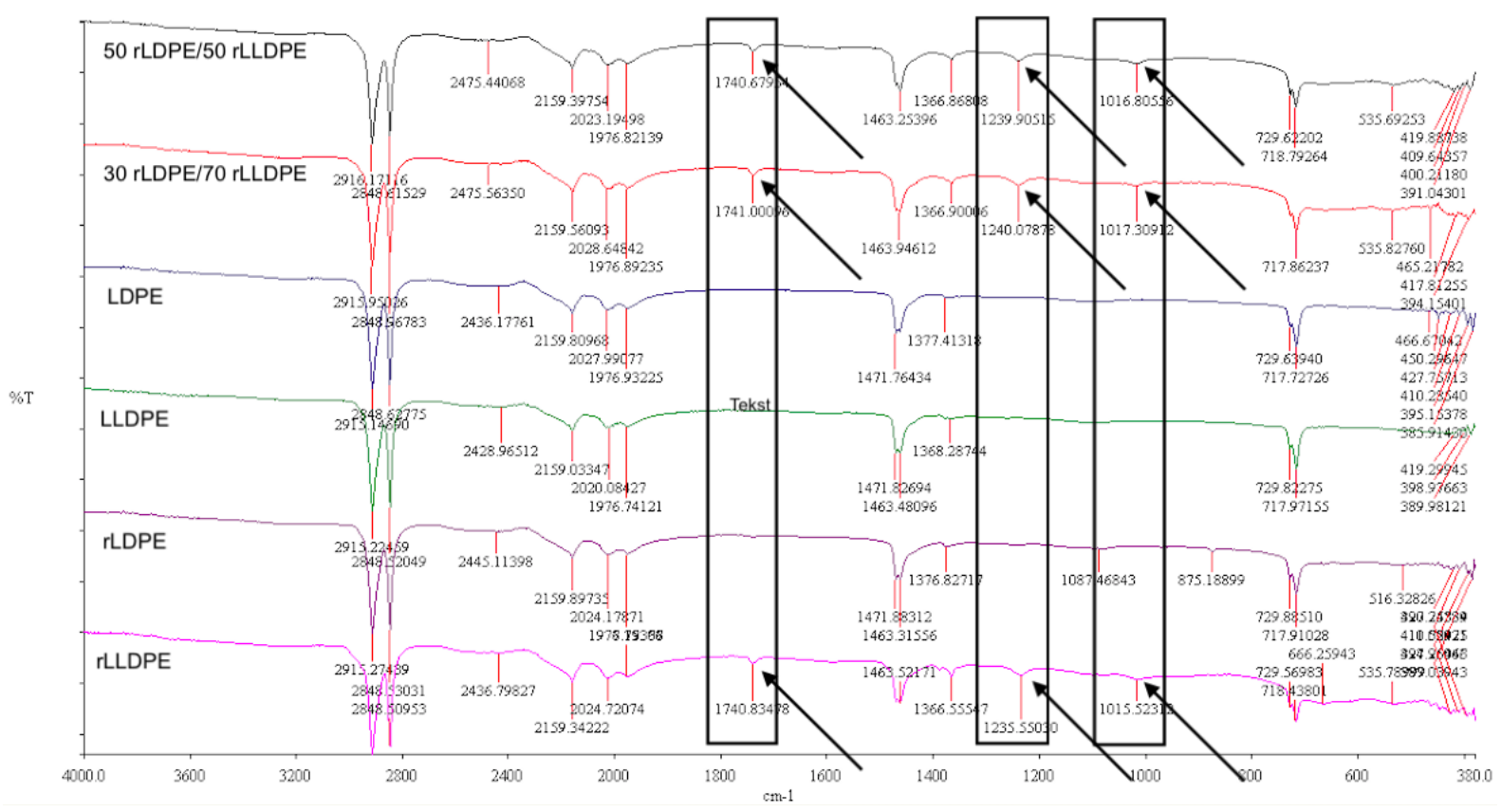

Fig. 9. FT-IR spectrum and the identification of characteristic bands (Spectrum Search Plus), (KnowItAll Informatics System, Academic Edition)

\section{Shrinkability}

Primary polymers were characterized by dimensional stability at elevated temperatures. A slight shrinkage in the machine direction was shown by the rLDPE film, while the shrinkage phenomenon was the highest for the regranulate blends, for which the highest content of rLDPE was the most important. According to the theory for thermoplastic polymers with a crystalline structure, further processes of structural and chemical changes occur, which results in a change of linear dimensions. During the processing, spherulites, like macromolecules, can be sorted out as a result of shearing and be the cause of the anisotropic behavior of the material (Table 4).

Rapid cooling in the manufacturing process has a slight crystallinity and little shrinkage, but 
Table 4. Shrinkability for virgin and recycled LDPE and LLDPE and recycled blends

\begin{tabular}{|c|c|c|}
\hline \multirow{2}{*}{ Samples } & \multicolumn{2}{|c|}{ Shrinkability (\%) } \\
\cline { 2 - 3 } & Machine direction, MD & Transverse direction, TD \\
\hline LDPE (A0) & 0,0 & 0,0 \\
\hline LLDPE (B0) & 0,0 & 0,0 \\
\hline rA & $-2,0$ & 1,0 \\
\hline rB & 0,7 & 0,0 \\
\hline rA30/rB70 & $-12,7$ & 4,7 \\
\hline rA50/rB50 & $-5,0$ & 2,0 \\
\hline
\end{tabular}

has a significant secondary shrinkage caused by recrystallization at elevated temperature [13].

According to literature data, the factors responsible for the occurrence of shrinkage include the proportion of crystalline and amorphous phases $[5,12,15]$ and the density of plastic. The estimated value of shrinkage can be about $1.0-1.5 \%$ for primary high pressure polyethylenes [15]. Higher density plastics have a greater processing shrinkage. Lower density materials crystallize less due to stronger chain branching, which leads to less shrinkage [5].

The study was aimed at determining the value of linear contraction (\%) in the heating phase and then cooling the film from regranulates and mixtures of these regranulates. The measurement concerns the change of linear dimensions in two manufacturing directions (MD and TD). The slight shrinkage and/or an increase in the linear dimensions observed for the re-granulate samples does not deviate substantially from the predicted shrinkage of polyolefins, while the mixtures with a different proportion of regranulates showed a significant shrinkage in the longitudinal direction (MD) and a tendency to increase the dimensions in the cross direction (TD) to the machine. In order to avoid such a significant change in linear dimensions due to the increased temperature (use), fillers can be used, both in the form of powder and short fibers, which helps to reduce shrinkage and stabilize linear dimensions $[1,8]$.

\section{Morphology observation}

Microscopic morphology of samples were obtained as free-standing flexible films, microscopically homogeneous, transparent and bubbles/impurities, as shown in Fig. 10.

We can see that the films prepared with virgin and recycled materials were continuous, transparent and flexible. Fig. 10 (c-d) shows the complete glossy surface of recycled films rLDPE and
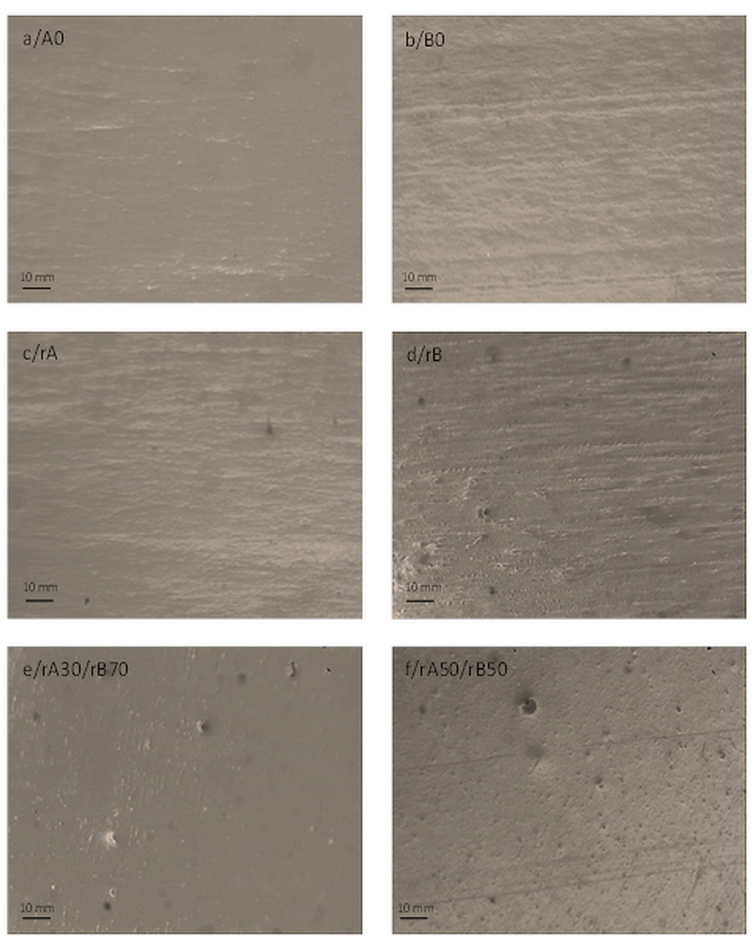

Fig. 10. PLM microscopy pictures of virgin and recycled LDPE and LLDPE and recycled blends (magnification $25 \mathrm{x}$ )

rLLDPE(e-f) with slight intercalations, which is typical of films produced on the basis of recyclates. However, we did not observe the presence of agglomerates on its surface, which might indicate the homogeneous dispersion of LDPE and LLDPE.

\section{CONCLUSIONS}

In this study, the rheological, thermo-mechanical, and structural properties in the films made of virgin and recycled LDPE and LLDPE, and their blends, were tested. The monolayer structure films were successfully produced through the single extrusion process. The results shown that MFI for recycled LLDPE film was 
higher, and for rLDPE was lower in comparison to virgin polymer.The results showed a significant increase of tensile properties like strength and elongation at break for recycled LDPE, and 50/50LLDPE compared to virgin polymers. Based on DSC studies, it was found that the melting temperature, and degree of crystallinity increases for the recycled blends. The PLM pictures showed that the films prepared with recycled materials and them blends are homogenous, continuous, and transparent. The puncture strength and energy of the 50rLDPE/50 rLLDPE blend was higher than the virgin polymers. Studies on the heat shrinkability of the samples showed that recycled films blends had a higher shrinkage in the machine direction compare to virgin polymers. The analysis of the blends FTIR spectra showed the contamination from rLLDPE, which did not appear in the spectra of the virgin polymers. Overall, the use of recycled post-consumer plastics have shown to be a useful method for mechanical recycling the monolayer films based in miscible polymers, creating a sustainable solution for an environmental problem.

\section{ACKNOWLEDGMENTS}

We would like to expressspecial thanks to Kruś, Granowo, Poland and Mr. Przemysław Muchowski for gratuitous preparation and transfer of granules for research and sharing photos used in the publication.

\section{REFERENCES}

1. Banasiak A., Sterzyński T. Właściwości kompozytów polimerowych PE + talk, Composites 2002, 2, 2.

2. Bula K., Knitter M., Properties of high-density polyethylene reinforced with pine-wood fillers, Drewno 2016, 59, 197.

3. Czarnecka-Komorowska D., Ciesielska D. Wpływ liczby obiegów na właściwości recyklatów polimerowych. Inżynieria i Aparatura Chemiczna 2005, 44, 3, 16-17.

4. Czarnecka-Komorowska D., Szostak M., Kujawa N., Kompozyty na bazie odpadów poliolefin napełnianych popiołami lotnymi, Inż. Ap. Chem. 2010, 49, 5, 31-32.

5. Fisher J. M. Handbook of molded part shrinkage and warpage. Plastic Design Library, William Andrew Inc., Norwich 2003.

6. Garbacz T. Structure and properties of cellular thin-walled cable coatings. Polimery 2012, 57, 1112, 91-94.
7. Garbacz T., Palutkiewicz, P. Geometrical properties of polymer films produced in blown molding extrusion process. Przetwórstwo Tworzyw 2016, 22, 3, 171, 116-125.

8. Jachowicz T., Godlewska A. Skurcz przetwórczy wyprasek wtryskowych napełnionych włóknem szklanym, Postępy Nauki i Techniki, 7, 2011.

9. Jeziórska R., Klepka T., Paukszta D. Polycarbonate/maleic anhydride grafted polyethylene/graphite composites. Polimery 2007, 294, 52.

10. Jumari N.F., Mohd-Yusof K. Comparison of Melt Flow Index of Propylene Polymerisation in Loop Reactors using First Principles and Artificial Neural Network Models, Chemical Engineering Transactions, 56, 2017, 163-168.

11. Madi N.K. Thermal and mechanical properties of injection molded recycled high density polyethylene blends with virgin isotactic polypropylene, Materials \& Design 2013, 46, 435-441.

12. Rosato D. V., Rosato D. V., Rosato M. G.: Injection Molding Handbook. Kluwer Academic Publisher, Norwell 2000.

13. Saechling, Poradnik, Tworzywa sztuczne, Wyd. 5., 2007.

14. Savargaonkar N., Patel R., Karjala T., Salibi P., Liu L. Fundamentals of abuse performance of LLDPE/ LDPE blends in blown film applications. TAPPI Conference 2014, 2, 1092-1116.

15. Sikora R. Przetwórstwo tworzyw wielkocząsteczkowych. Wydawnictwo Edukacyjne. Warszawa 1993.

16. Sykutera D., Bieliński M. Wybrane właściwości recyklatu polipropylenowego pochodzącego z porowatych wyprasek formowanych metodą wtryskiwania, Polimery 2014, 7-8, 602.

17. Wunderlich B., Macromolecular Physics; Crystal nucleation, growth, annealing, Academic Press: New York, 1976.

18. EN 14477 Packaging - Flexible Packaging Material - Determination of puncture resistance - testmethods.

19. ISO 1133-1:2011 Plastics - Determination of the melt mass-flow rate (MFR) and melt volume-flow rate (MVR) of thermoplastics - Part 1: Standard method.

20. ISO 11357-2:2013 Plastics - Differential scanning calorimetry (DSC) - Part 2: Determination of glass transition temperature and glass transition step height.

21. PN-EN ISO 527-3 Plastics - Determination of tensile properties - Part 3: Test conditions for films and sheets.

22. PN-EN ISO 11501:2005 Plastics - Film and sheeting - Determination of dimensional change on heating. 